\title{
Designing a Road Accident Management Information System for Tehran Province, Iran (Case Study: Tehran-Qom, Tehran-Karaj, and Tehran-Saveh Routes)
}

\author{
Zahra Mollahmohammad Alian Mehrizi ${ }^{1} \mathbb{D}$, Maryam Samani ${ }^{2}$
}

Date of submission: 27 May 2019, Date of acceptance: 13 Aug. 2019

\section{Original Article}

Abstract

INTRODUCTION: One of the main weaknesses and problems in the field of road accident management is the lack or non-use of appropriate information systems. The overall aim of this study is to reduce the impact of road accidents in the west, southwest, and south routes of Tehran Province, Iran, by designing Management Database responsible for road accidents.

METHODS: This was an applied study performed using the descriptive-analytical method in which the data entry and analysis were conducted in the Geographic Information System (GIS) environment in line with the objectives. Then, according to different requirements of the various users, an appropriate analysis was performed on the layers and the software spatial analysis was applied in line with the main objective of the study. In the next step, the desired outputs were extracted from the system and the main output, i.e. the comprehensive database of spatial data required to manage road accidents, was provided to the management levels of various organizations for planning.

FINDINGS: In this study, the accident-prone areas in the studied routes were identified using the kernel density estimation (KDE) method.

CONCLUSION: Performing various analyses on geographical and descriptive information and providing appropriate outputs and also sharing them can play an effective role in reducing injuries caused by road accidents.

Keywords: Road Accident Management; Relief Centers; Spatial Analysis; Tehran Province Access Routes; Disaster Management Information System (DMIS)

How to cite this article: Mollahmohammad Alian Mehrizi Z, Samani M. Designing a Road Accident Management Information System for Tehran Province, Iran (Case Study: Tehran-Qom, Tehran-Karaj, and Tehran-Saveh Routes). Sci J Rescue Relief 2019; 11(3): 174-83.

\section{Introduction}

$\mathrm{T}$ oday, road accidents impose a lot of financial, human, and time costs on governments and communities worldwide. These costs are relatively higher in third world countries compared to the industrialized countries, accounting for a large percentage of deaths, especially in road accidents. In addition to accidents, the occurrence of natural disasters on roads such as landslides, avalanches, landslides, winds, high temperatures, fog, dust, road slip, snow, blizzards, and frost, and other natural disasters is inevitable and requires relief delivery in the shortest time possible. In road accidents, there is always a wide range of information, only with the optimal management and use of which basic steps can be taken to reduce road accidents (1).

Preparing a Geographic Information System (GIS) for unexpected events taking into account scientific and practical criteria, using a specific method, and considering short-term and long-term basic needs, along with attention to the quality of information used (in terms of accuracy) will significantly help the officials in the fields of planning, decision-making, and policy-making (2).

Investigating and analyzing potential and

1- PhD, Member of Academic Board, Applied Science Higher Education Institute Red Crescent Society of the Islamic Republic of Iran, AND Research Center for Emergency and Disaster Resilience, Red Crescent Society of the Islamic Republic of Iran, Tehran, Iran

2- MA, Disaster Management Information System, Research Center for Emergency and Disaster Resilience, Red Crescent Society of the Islamic Republic of Iran, Tehran, Iran

Correspondence to: Zahra Mollahmohammad Alian Mehrizi, Email: zmehrizi@yahoo.com 
actual hazards in the routes under study and designing the responsive management information system in road accidents can be effective in increasing the managerial capacity of the bodies involved in the area of road transport accidents.

The overall purpose of this study is to reduce the impact of road accidents in the west, southwest, and south routes of Tehran Province (Tehran-Karaj, Tehran-Qom, and Tehran-Saveh routes) by designing a management database responsible for road accidents. In order to achieve this goal, items such as preparing electronic maps, banks and information resources, the possibility of fast information updating, identifying high-traffic areas of Tehran Province in the study routes, performing analyses and providing appropriate solutions, access of various users to the required analyses according the definition of access levels in the database, and investigation of the current situation of the relief centers responsible for road accidents (road rescue bases, emergency services, roadhouses and traffic police) in the desired routes were covered in the study.

Road accidents are one of the most important challenges for road transport with many causes and many material and spiritual damages that are sometimes irreparable. In addition to imposing a heavy burden on the economy of human societies, financial and human losses caused by accidents create major problems for public health and obstacles to development (3). Therefore, identifying the causes of road accidents and preventing such accidents is very important in reducing its harmful and sad impacts (4) Additionally, an investigation of the natural hazards taken place in the past shows that the country's roads do not have the necessary safety to deal with crises such as landslides, frost, and road slippage, thus identifying the dangers and accidents that threaten these roads, along with accident-prone and unsafe points of roads in the event of natural hazards is considered useful and important (5).

In most successful countries in the field of road transport safety, the provision of relief activities along the roads is divided into three sections of medical relief, road relief, and technical assistance. In Iran, the relief agencies in road traffic accidents are traffic police, emergency services, the Iranian Red Crescent Society (IRCS), and road maintenance organization, the distribution of which on the study routes is illustrated in Map depicted in Figure 1.

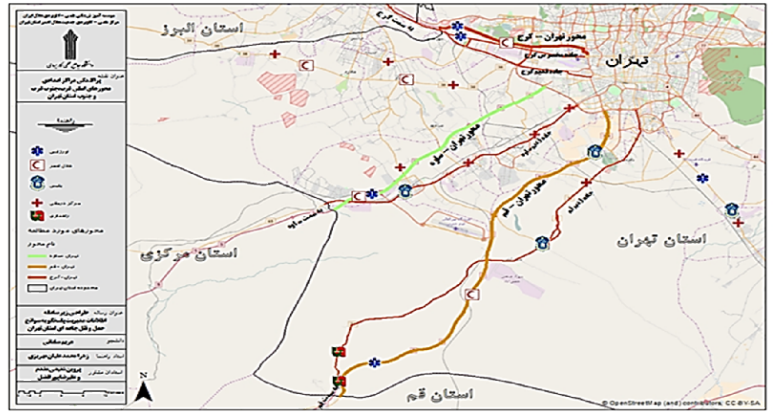

Figure 1. Map of distribution of roadside relief centers of the studied routes of Tehran Province, Iran

Through creating an appropriate ground, the GIS capabilities can be effective in managing road accident crisis. Due to the capabilities of this system, today the implementation and as a result, the level of access to this system and related technologies is expanding rapidly and continuously; So that its penetration rate in the vital infrastructure and executive organizations of the country has increased and its application in normal conditions and all kinds of crises has become inevitable (6).

In a study entitled "GIS application in Road Accident Relief", Tousi et al. pointed out the benefits of this information system in road accident relief (7).

Examining the service status of existing roadside relief centers and constructing new relief centers if necessary, automating relief work in order to reduce relief time to accident victims, and reducing human casualties in road accidents and determining the coordinates of the accident site are among the important objectives of the current study.

Masoumi et al. in a study on the "Application of evolutionary algorithms and spatial information systems in road accidents", examined the application of these algorithms in reducing and minimizing the effects of road accidents. The objective in this study was to provide a routing algorithm to announce the best route to relief staff starting from the best relief base by receiving the parameters such as street traffic, time of operation, and map of possible routes from the GIS system (8).

Talebi and Faryabi studied the role of information systems in road accident management in a study entitled "Using GIS in road accident management". This study introduced a provincial experience in the use of GIS in the analysis of transportation information, especially road accidents. In this study, by designing software in the GIS environment and analyzing spatial and 
descriptive data of accidents and using the genetic algorithm (GA) method, it was tried to provide a model to predict the probability of accidents in the routes of West Azerbaijan Province, Iran. This analysis was also used in software development to better locate roadside relief bases (9).

In a study by Effati and Rajabi titled as "Providing a way to determine road accident hotspots using spatial information system and multi-criteria decision making processes" pointed out that spatial information system as an important science and technology to deal with the involvement of spatial factors in decision-making can play a significant role in accident management and determination of road accident hotspots. In this study, the parameters effective in determining the accident-prone areas of roads were investigated and using spatial information systems and multi-criteria decision-making (MCDM) processes, a new method was presented to determine road accident hotspots in the form of a risk map and this method was finally compared with the existing statistical methods (10). In a study, Nourzad et al. explored the geographical distribution and causes of deaths and its effective factors in road accidents leading to death in Ardabil Province from July 2012 to 2014 using GIS. (11)

Reviewing numerous documents and related records, it was observed that in the field of designing responsive road accident management information systems in a way that meets the information needs of organizations involved in road accident management, no studies were conducted and the available case studies were based on the evaluation and analysis of the factors involved in road events, especially road accidents using GIS. The present study, due to the involvement of various parameters in the occurrence of road transport accidents (natural and man-made factors and potential and actual hazards), proposed a system design that by collecting and analyzing the required information layers and updating these layers in the GIS environment, could be applied in reducing the effects of road accidents by the responsible and relief organizations with different access levels.

Study area: Due to its commercial and social aspects, geographical location, and position on the route of important access roads to different regions of the country, Tehran Province has a special place in moving cargo and passengers in the country. Moreover, this province is one of the main centers of the country's industry and the industries are more focused along the roads entering Tehran, especially on the Tehran-Karaj, Tehran-Saveh, and Tehran-Qom routes. The industrial route of western Tehran with a length of approximately more than $140 \mathrm{~km}$ is the longest and most dense route in terms of the establishment of industries and population centers. It is noteworthy that today Tehran, as a major industrial hub, has an active connection with the surrounding cities in almost all directions, even at relatively long distances, and needs consideration from the perspective of accidents due to the establishment of population centers in the margins of the transportation routes (12), which also highlights the importance of investigating road accidents in this province. The climate type and the different geological structure of this province also lead to the special events in the communication routes of this province, needing basic steps to be taken to control and minimize the effects of these accidents.

The study area in the present study consisted out the three transportation routes of TehranKaraj, Tehran-Qom, and Tehran-Saveh, which are briefly described below.

Tehran-Karaj freeway: The 33-km-long Tehran-Karaj highway carries the traffic load of more than 10 western and northwestern provinces. The huge volume of passengers to Tehran, as well as the population living in Karaj due to the short distance to Tehran and the location of major industrial and occupational centers affiliated with industry that travel on this route, has made the Tehran-Karaj communication route one of the most important urban transportation routes in the country and also one of the busiest roads in the region. The Tehran-Karaj-Qazvin route continues through Karaj along the southern Alborz mountain range and is considered as the most important transit road in the country. The high volume of traffic on this route, the position of industrial centers and consequently the establishment of many residential settlements with a large population on the outskirts of this transportation route has doubled the risk of accidents in this route. In terms of natural disasters, snow and blizzards put this route at serious risk. Furthermore, the presence of flooded rivers on the upper reaches of this highway, such as the Karaj-Chitgar-Kan-Farahzad-Hesarak, Evin, and Darkeh Rivers, are considered a threat in certain seasons of the year if they overflows. The existence of many industrial hubs on the side of this highway 
is one of the potential dangers of this route, the importance of studying which for managerial planning in the context of road accidents should not be overlooked. Figure 2 demonstrates the location of the Tehran-Karaj freeway as well as the distribution of roadside relief centers on this route.

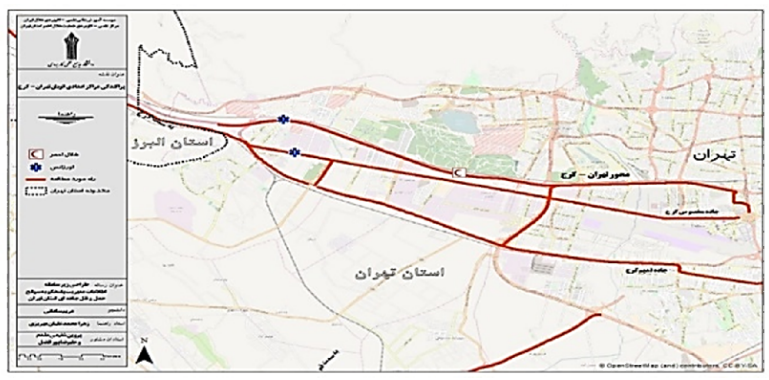

Figure 2. Map of Tehran-Karaj freeway location and distribution of roadside relief centers in the study route

Tehran-Qom freeway: This 154-km-long route passes by Hoz-e Soltan or the Salt Lake of Saveh and is the oldest communication route between Tehran and the southern cities of the country. The Tehran-Qom route is one of the most important communication lines and the arterial road connecting Tehran to the southern provinces of the country, which due to its proximity to the holy shrine of Imam Khomeini and Golzar-e Shohada in Behesht-e Zahra, many citizens and pilgrims pass through it daily. The high volume of traffic on this route in all seasons, the presence of numerous industrial towns on the side of the freeway, and the existence of natural disasters such as very severe dust storms, which is one of the potential dangers of this freeway, have increased the risk potential in this route, revealing the importance of studying the route (13). The position of the Tehran-Qom freeway and the distribution of roadside relief centers on this route are indicated in the map displayed in Figure 3.

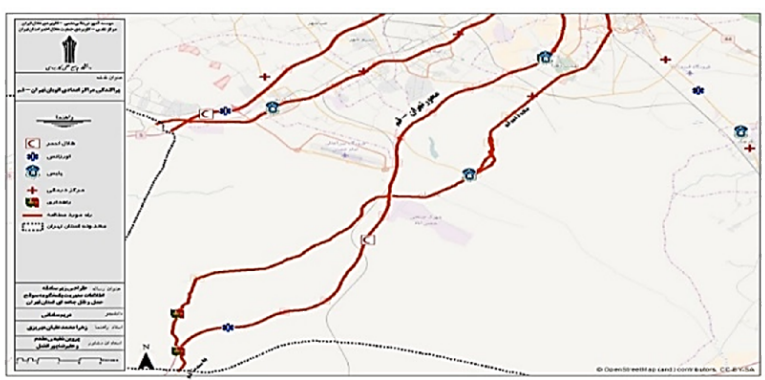

Figure 3. Map of Tehran-Qom freeway location and distribution of roadside relief centers in the study route
Tehran-Saveh freeway: This route is $134 \mathrm{~km}$ long and connects Tehran with the cities of the western and southwestern provinces of the country. This route is also at risk of sandstorms due to its location in hot and dry climates and crossing desert areas like the Tehran-Qom freeway. The high volume of traffic in this route and the existence of industrial centers like other western and southwestern routes of Tehran Province in the margins of this transportation route is also one of the dangers that cause various accidents in this route and increases the importance of studying it to reduce the risks of road accidents. The position of the Tehran-Saveh freeway and the distribution of roadside relief centers on this route are indicated in the map shown in Figure 4.

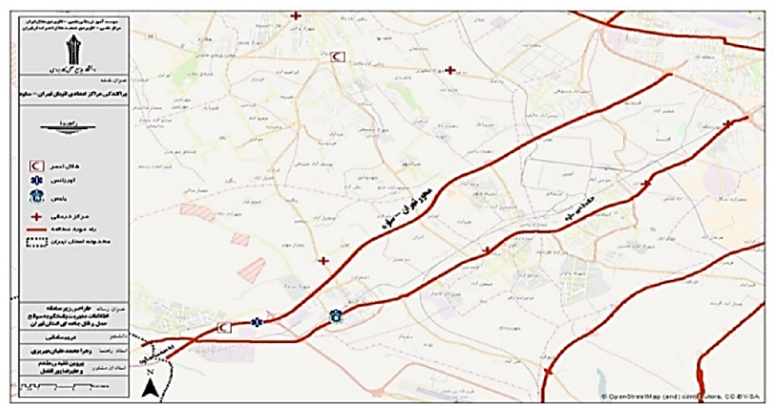

Figure 4. Map of Tehran-Saveh freeway location and distribution of roadside relief centers in the study route

\section{Methods}

This was an applied study conducted using the descriptive-analytical study method. In order to collect information, the library-field method was adopted. Data entry and analysis were performed in the GIS environment in accordance with the study objectives. The study area in the present study included the west, southwest, and south routes of Tehran Province (Tehran-Karaj, Tehran-Qom, and Tehran-Saveh routes).

In order to design a comprehensive database of spatial data required to manage road accidents, in the first stage, using the studies, the desired information layers were identified and after preparation entered GIS in a compatible format. Using GIS, after obtaining the digital data of the reference land required in the preparation of road accident management information system, according to different needs of different users, appropriate analyses were performed on the layers in ARCGIS environment (V.10.3) and using the 
spatial analysis models of this software such as Thiessen analysis, kernel density estimation (KDE), distance, buffer analysis, spatial analysis, etc. In the next step, the desired outputs were obtained from the system and displayed to the system users in the formats required them. These outputs included maps of high-risk areas in the routes under study (road accident risk zoning maps), fault maps, maps of roads of Tehran Province and alternative roads, maps of roadside relief centers, maps of industrial centers in the study area, the map of population centers in the range of transport routes studied, the map of service and welfare centers, the map of natural and man-made terrains, the map of natural and man-made accidents, and so on. These maps along with their descriptive information and the provincial road accident database were applied aiming to reduce the vulnerability to road accidents and to provide effective and timely response to these accidents in the study areas. This system consisted of models for estimating road accident casualties, zoning of road accidentprone areas, identifying areas covered by road accident relief centers, and locating road accident relief centers and vulnerable areas including faults, flooding areas, landslides, and models for risk and vulnerability assessment.

\section{Findings}

In the spatial analysis of road accidents in Tehran Province in general and the studied routes in particular, two spatial analyses were used. Although the results of these analyses will be presented in the following, their methodology is mentioned here:

\section{A: Distribution analysis}

In this type of spatial analysis of road accidents, the location of road accidents extracted from IRCS accident management system relative to different terrains. Transport routes, relief organizations, natural and man-made terrains, etc. are among these terrains. Examining the relative position of these terrains relative to the points of occurrence of road accidents can lead to the extraction of spatial relationships among them.

\section{B: Estimation of road accident density}

Several methods have been developed as spatial patterns of accident sites. In general, the methods of identifying and prioritizing accident hotspots can be divided into the following two groups:

- Reactionary or accident-based approach: which relies on statistical analysis of basic accident information to determine road safety problems.

- Preventive or observation-based approach: which emphasizes the analysis of the physical and functional characteristics of the road to identify the safety problems of the existing roads or road construction projects. This method is called road safety inspection, the use of which has expanded rapidly over the past decade.

In this study, with the reactionary approach based on the accidents registered in the Red Crescent Society disaster management information system (DMIS) and using the accident hotspot dispersion estimation method by GIS space analysis during the study period, the accident-prone areas were identified and classified.

The KDE method is one of the spatial analysis analyses in the Arc GIS software which is used to estimate the density for linear and point terrains. This analysis is one of the best ways to identify hotspots that can be applied to identify accident hotspots.

In this method, using a specific function, a range is determined around each point, which becomes narrower (fainter) by moving away from that point. The area closer to the accident site will be stronger and the farther areas will be fainter. In other words, the areas with the higher density of accidents will be much stronger than the areas with the lower number of recorded accidents. The map depicted in Figure 5 displays the accidentprone areas of the communication routes studied in the current study.

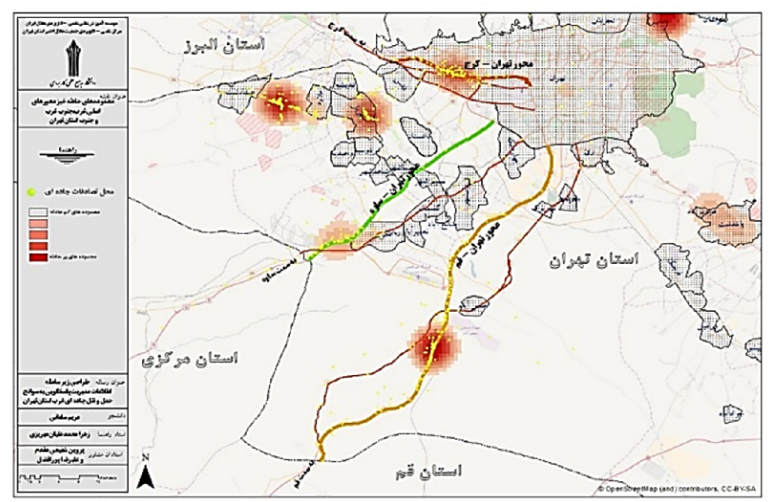

Figure 5. Map of accident-prone areas of communication routes studied during the years (2012-2014)

The analysis results in the studied routes show that the order of priority of the three most risky areas will be as follows: 
Table 1. Intercity relief bases, Reference: Iranian Red Crescent Society (IRCS)

\begin{tabular}{lcccc}
\hline Route name & Base name & Address & Longitude & Latitude \\
\hline Tehran-Karaj & Chitgar base & Tehran-Karaj highway & 51.2142 & 35.7197 \\
Tehran-Saveh & Pay toll & First Tehran to Saveh toll & 51.0139 & 35.47 \\
Tehran-Qom & Hassanabad & Hassanabad Industrial Zone & 51.1749 & 35.3096 \\
\hline
\end{tabular}

- Tehran-Qom route: an area of ten kilometers from the end of Hassanabad industrial town to Qom

- Tehran-Saveh route: seven kilometers leading to the second Tehran-Saveh pay toll

- Tehran-Karaj route: five kilometers of highway route in front of Chitgar Forest Park.

The most important information layers used in the analyses, which include the set of the information layers indicating the distribution of organizations involved in road relief, are as follows:

- Intercity rescue bases of IRCS, which include three active bases in the study areas. The distribution of these bases in the studied communication routes is as described in Table 1.

Although there were a high number of IRCS centers in the region, especially in urban areas, due to the operational and specialized nature of the established teams and their operation at different times of the day, only permanent inter-city relief bases are shown. Figure 6 shows the dispersion of intercity relief bases in the studied routes.

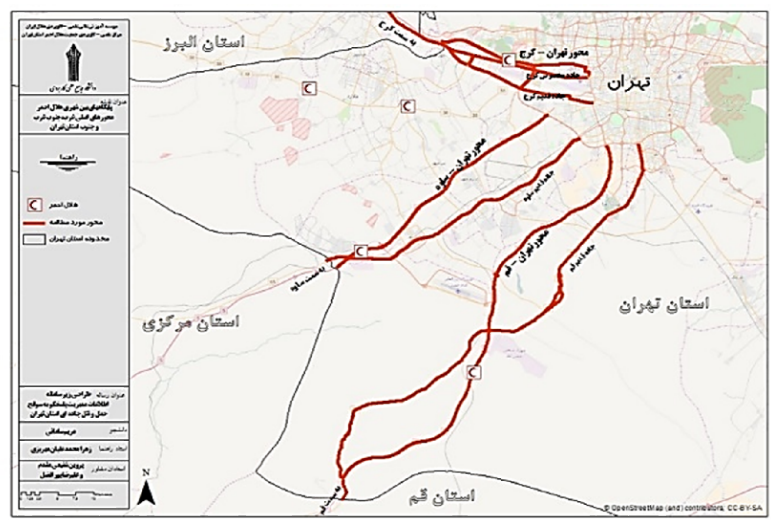

Figure 6. Map of distribution of the Iranian Red

Crescent Society (IRCS) intercity relief bases in the study routes
- Road emergency bases, which include four active bases in the study routes. The distribution of these bases in the studied communication routes is as described in Table 2 (Figure 7).

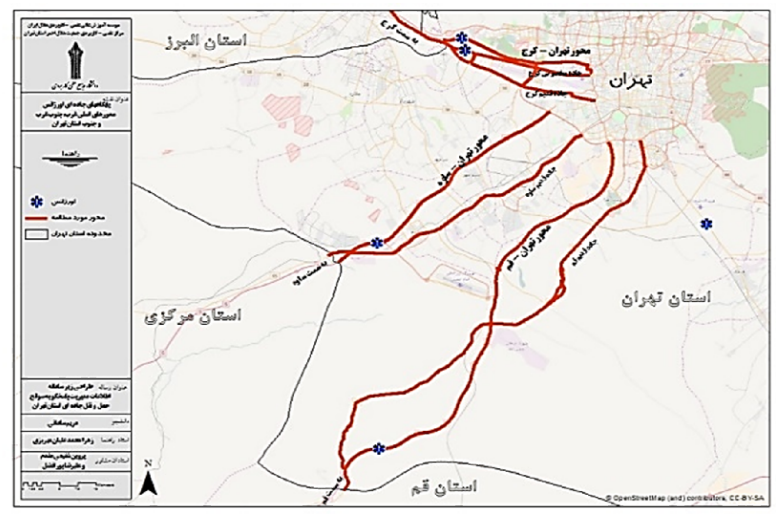

Figure 7. Map of distribution of road emergency bases in the communication routes studied

- Road traffic police bases, which are distributed in the three exit points of the studied routes. The distribution of the traffic police centers in the communication routes studied is as described in Table 3 (Figure 8).

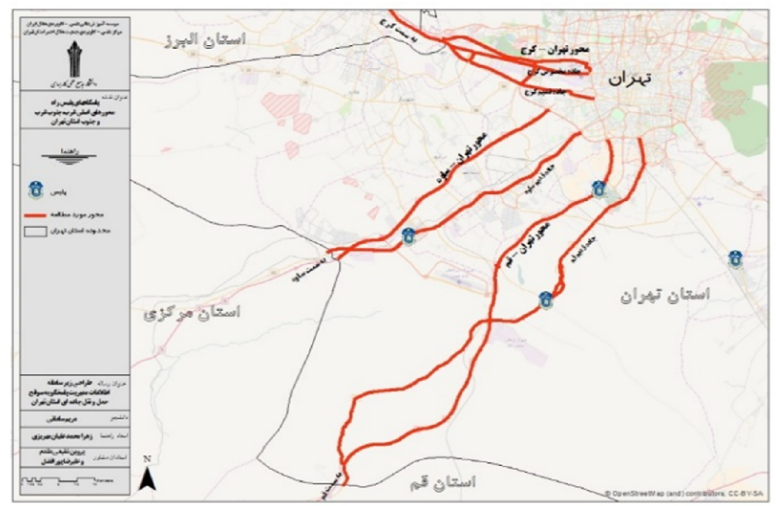

Figure 8. Map of distribution of traffic police centers in the communication routes studied

Table 2. Road emergency bases in the studied routes, Reference: Tehran Emergency Department

\begin{tabular}{l|cc|c|c} 
Route name & Base name & Address & Longitude & Latitude \\
\hline Tehran-Karaj & Tehran-Karaj Highway & Kilometer 18 of Tehran-Karaj Freeway & 51.142263 & 35.745605 \\
Tehran-Karaj & Special Road & Kilometer 18 of Special Road & 51.145175 & 35.728490 \\
Tehran-Saveh & Pay toll & First tolls of Tehran-Saveh Freeway & 51.018490 & 35.466930 \\
Tehran-Qom & Hafezieh & Hafezieh Tehran-Qom Freeway & 51.033665 & 35.196114 \\
\hline
\end{tabular}


Table 3. Road traffic police bases in the communication routes studied in Tehran Province, Iran, Reference:

Traffic Police of NAJA, abbreviated as RAHVAR

\begin{tabular}{l|ccc|c} 
Route name & Police station name & Address & Longitude & Latitude \\
Tehran-Saveh & Robat Karim & Robat Karim & 51.068162 & 35.474443 \\
Tehran-Qom & Tehran-Qom Highway & Tehran-Qom tolls & 51.352510 & 35.546334 \\
Tehran-Qom & Hassanabad checkpoint & Kilometer 40 of old Tehran-Qom road & 51.280917 & 35.394775 \\
\hline
\end{tabular}

- There were 5 medical centers in the study routes. It is worth mentioning that hospitals and medical centers in Tehran, Eslamshahr, Robat Karim, and Shahriar cities are responsible for admitting the casualties of road accidents of the west Tehran Province (Figure 9).

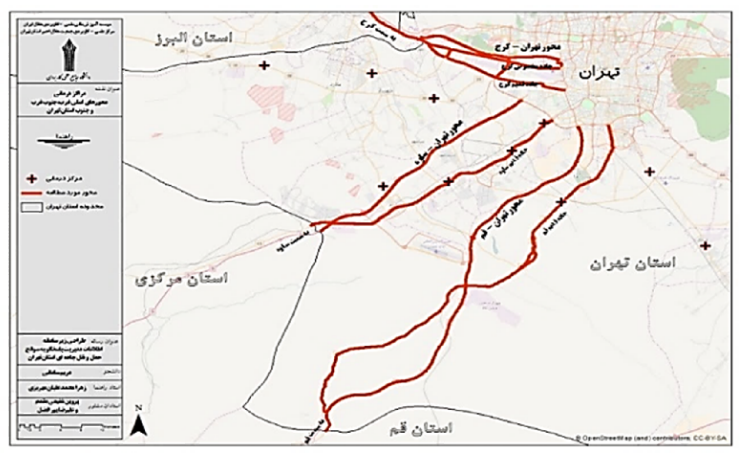

Figure 9. Map of distribution of medical centers in the communication routes studied

The distribution of medical centers is illustrated in Table 4.

Table 4. Medical centers within the communication routes studied in Tehran Province, Iran

\begin{tabular}{lcc} 
Route name & $\begin{array}{c}\text { Medical } \\
\text { center name }\end{array}$ & Address \\
\hline Tehran-Saveh & $\begin{array}{c}\text { Alard Health } \\
\text { Home }\end{array}$ & Alard village \\
$\begin{array}{l}\text { Tehran-Saveh } \\
\text { old road } \\
\text { Tehran-Saveh } \\
\text { old road } \\
\text { Tehran-Saveh } \\
\text { old road } \\
\text { Tehran-Qom } \\
\text { old road }\end{array}$ & Bahramabad & $\begin{array}{c}\text { Sultanabad } \\
\text { Beginning of the } \\
\text { old road } \\
\text { Bahramabad }\end{array}$ \\
\hline
\end{tabular}

There were a number of road maintenance bases on the Tehran-Qom route and the other two routes lacked a permanent road maintenance base. However, road maintenance teams are deployed along the road in occasional and seasonal plans to respond effectively to road accidents. The distribution of the road maintenance centers is as described in Table 5 (Figure 10).

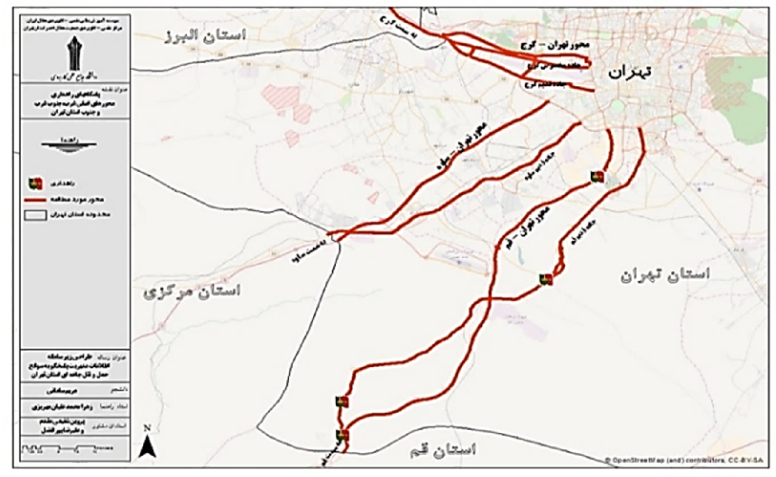

Figure 10. Map of distribution of road maintenance centers in the communication routes studied

The distribution map of the service and welfare centers in the study routes, including telecommunication centers, car repair and service centers, roadside mosques, gas stations, restaurants, and roadside parking lots is demonstrated in Figure 11.

Communications including land, air, and rail communication services and infrastructure within the study area were as follows:

- Routes under study

- Rail

- Airports

- Roads

- Bridges

- Tunnels

Table 5. Road maintenance centers in the studied routes, Reference: Road Maintenance Organization

\begin{tabular}{|c|c|c|c|c|}
\hline Route name & $\begin{array}{l}\text { Road maintenance } \\
\text { center name }\end{array}$ & Address & Longitude & Latitude \\
\hline Tehran-Qom & Tehran & Kilometer 8 of the Tehran-Qom highway & 51.353565 & 35.543144 \\
\hline Tehran-Qom & Hafezieh & Kilometer 65 of the Tehran-Qom highway & 50.981205 & 35.166758 \\
\hline Old Tehran-Qom route & Hassanabad & Kilometer 24 Old Tehran-Qom route & 51.278244 & 35.394718 \\
\hline Old Tehran-Qom route & Nalbandan & Kilometer 60 Old Tehran-Qom route & 50.957466 & 35.198008 \\
\hline
\end{tabular}




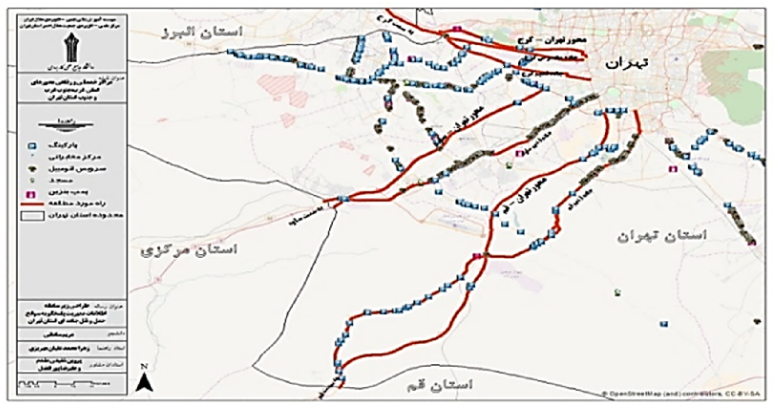

Figure 11. Map of distribution of service and welfare centers in the communication routes studied

Figure 12 represents the distribution of communication routes (rail, road, and air) in the study area.

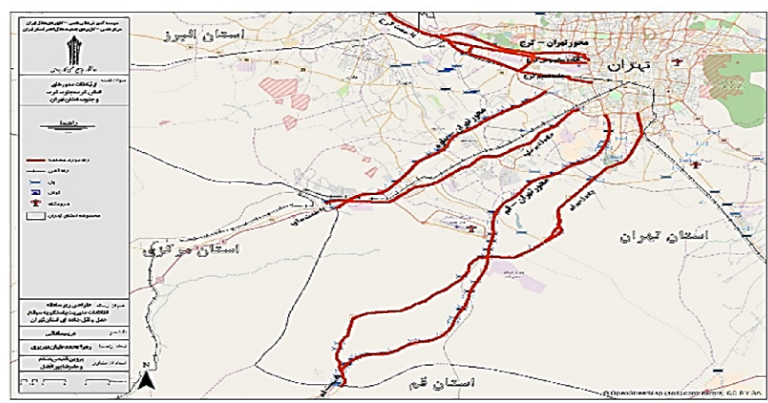

Figure 12. Map of distribution of communication routes studied

Another category of data included data on the neighboring settlements of the routes and the required descriptive information on the rural and urban settlements and the legal limits of cities. According to Figure 13, a large part of the study routes is adjacent to human settlements.

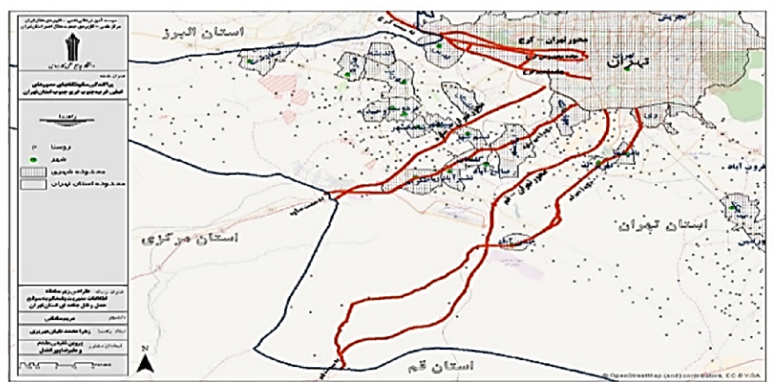

Figure 13. Map of distribution of human settlements in the vicinity of the routes studied

Understanding the risks in the study area is one of the most important pillars of decision-making and decision-making support in responding the relief issues. The data of various natural and unnatural hazards occurred lay in this group of information layers, with their distribution in the study area shown in Figures 14 and 15.

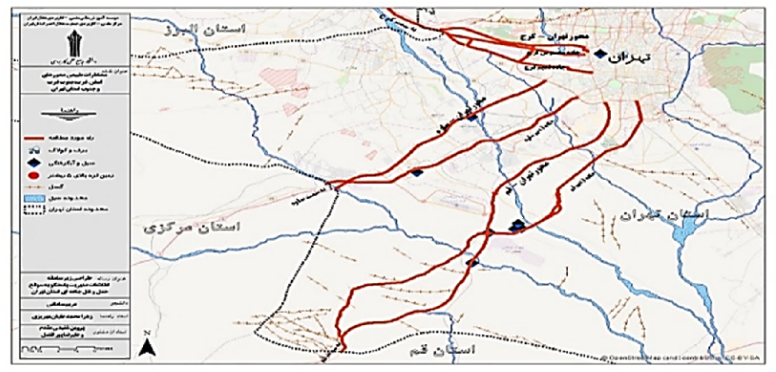

Figure 14. Map of distribution of natural disasters in the vicinity of the routes studied

These risks include:

- Natural road accident sites

- Unnatural road accident sites

- Accident-prone and dangerous road areas

- Faults

- Flooding areas

- Earthquakes above five Richter

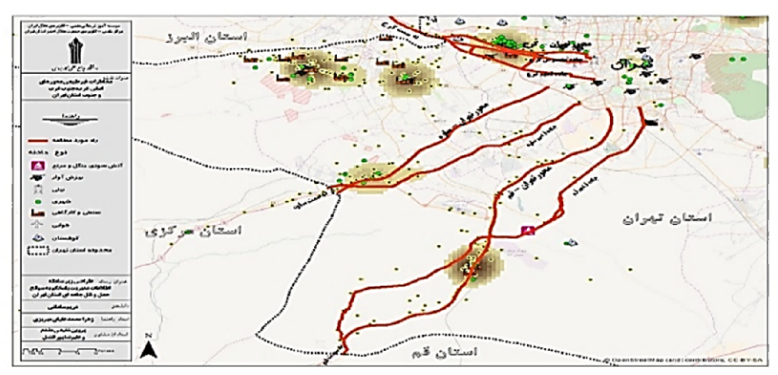

Figure 15. Map of distribution of unnatural events in the vicinity of the routes studied

Natural terrains can always contribute to the aggravation or relief of accidents. In the western and southern routes of Tehran Province, due to the relative uniformity of natural terrains and landscape, only the information of the permanent and seasonal rivers is given. Figure 16 shows the natural waterways of the west, southwest, and south Tehran Province.

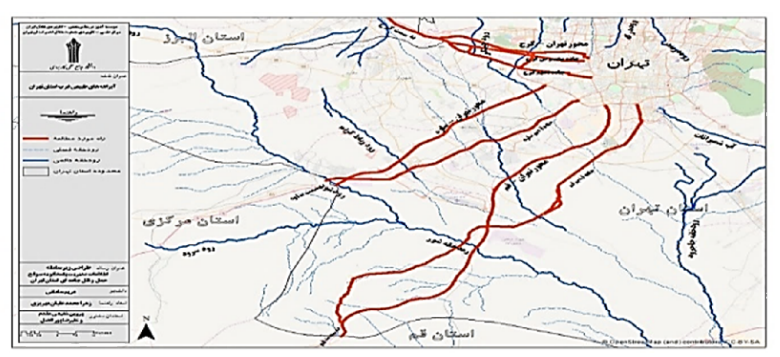

Figure 16. Map of distribution of natural waterways in the study areas of Tehran Province, Iran 
Figure 17 shows the distribution of man-made terrains in the vicinity of the studied routes.

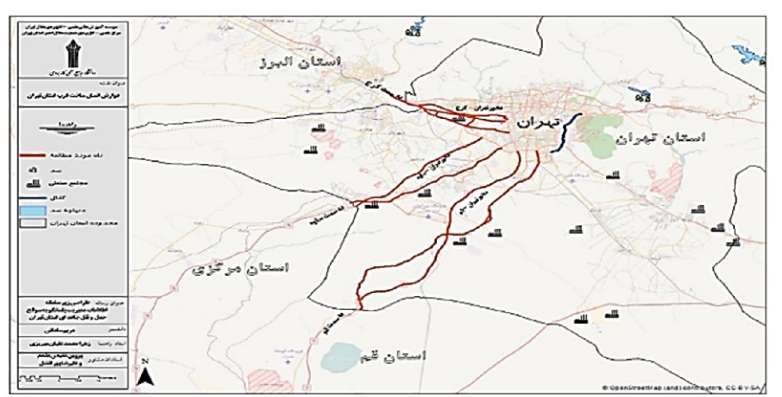

Figure 17. Map of distribution of man-made terrains in the communication routes studied in Tehran Province, Iran

\section{Discussion and Conclusion}

Designing a road accident management system is one of the most important requirements in accident management. Such a system can play a role in two grounds: establishing spatial databases with features such as storing, query, and retrieving accident information, as well as preparing and providing data for spatial analyses such as creating a risk map.

One of the most important problems in responding to road accidents in Iran is the diversity of organizations responsible for road relief. It that the GIS obtained from this study, in addition to sharing the data of all organs, if the guidelines for responding to accidents are developed, can monitor the performance of relief bodies and measure their responsiveness. If the required information and continuous updating of this data are met, the system designed to respond to road accidents can also provide solutions in areas such as determining accident hotspots, estimating traffic volume in specific time periods, spatial analysis of relief centers, determining the nearest responsible centers in accidents, offering the shortest or fastest way to send relief teams, offering alternative routes, and determining legal privacy and safety limits of terrains, hence reducing the risk of injuries and casualties in road accidents.

With this system, outcomes such as reducing the response time in accidents, reducing the information to the responsible bodies, modifying the accident hotspots identified in the route, and strengthening the infrastructure in the face of natural and unnatural accidents can be expected.

In this study, the analysis of accident potential of the studied routes in the current situation based on the accidents occurred in the three-year period (2012-2014) and the use of KDE method in GIS, the high-risk areas in terms of road accidents were identified. The areas identified in this model for each of the studied routes are as follows:

- Tehran-Qom route: an area of ten kilometers from the end of Hassanabad industrial town to Qom

- Tehran-Saveh route: seven kilometers leading to the second toll of Tehran-Saveh

- Tehran-Karaj: five kilometers from the highway in front of Chitgar Forest Park

It is worth noting that scrutinizing risky areas and determining accident hotspots requires more detailed and more comprehensive field studies.

\section{Acknowledgments}

The present was extracted from a M.Sc. thesis performed at the Helal-e-Iran Applied Science Higher Education Institute affiliated to the University of Applied Science and Technology.

\section{Conflict of Interests}

Authors have no conflict of interests.

\section{References}

1. Amini A, Salami M, Mehrvarzan M. Intelligent system of management and road accidents and violation publicity. Rahvar 2012; 9(19): 35-49. [In Persian].

2. Valadbeigi M, Abdollahi M, Taghipour AA. Presenting the proposed model of geographic information system in crisis management of the country's cities. Payam Emeni 2015; 12(53). [In Persian].

3. Sherafati A, Kashfi S, Mehmandar MR. The study of effective factors on road accident management in Summer 2013 Lorestan Province. Rahvar 2013; 10(22): 31-43. [In Persian].

4. Rahmani M. Zoning of road accident-prone with determine the black spots by using GIS (case study: Malayer-Hamedan road). Environmental Based Territorial Planning (Amayesh) 2016; 9(34): 155-75. [In Persian].

5. Borna R, Vahedpour GH. Investigation of natural hazards management in accidents road control case: Karaj-Chalous. Journal of Regional Planning: 2011; 1(3): 81-92. [In Persian].

6. Kalantari Oskuei A, Modiri M, Alesheikh A, Hosnavi R. Providing a framework for risk assessment in Geographic Information Systems (GIS) and Corporate Spatial Data Infrastructure 
(SDI) based on fuzzy logic Case study: agricultural organization of east Azarbaijan province. Journal of Emergency Management 2015; 3: 31-44. [In Persian].

7. Tousi AM, Rezvani MH, Atashi D. GIS application in road accident relief. Proceedings of the Geomatic Conference; 2007 Apr 21-22; Tehran, Iran. [In Persian].

8. Masoumi F, Masoumi MR, Jafarieh F. Application of evolutionary algorithms and spatial information systems in road accidents. Proceedings of the $1^{\text {st }}$ National Conference of Roadway and Railway Accident and Futurities; 2009 Dec. 10; Zanjan, Iran. [In Persian].

9. Talebi B, Faryabi F. Using GIS in road accident management [Online]. [cited 2014]; Available from: URL: http://www.rmto.ir/141/Maghalat141 [In Persian].

10. Effati M, Rajabi MA, Samadzadegan F. Providing a way to determine road accident hotspots using spatial information system and multi-criteria decision making processes. Proceedings of the Geomatics Conference; 2009 May 10; Tehran, Iran. [In Persian].

11. Nourzad S, Nazmifar H, Valizadeh B, Sadeghieh Abhari $\mathrm{H}$, Farzaneh I. Investigating the geographical distribution and causes of death and the factors affecting it in road accidents leading to death in Ardabil province. Ardabil Univ Med Sci Health Servic. 2012[In Persian].

12. Pourahmad A, Falahian N. A survey of development of industrial axes around Tehran. Geographical Research 2005; 37(53): 173-92. [In Persian].

13. Ebadinejad A, Osanlou A. The study of the effect of wind on traffic safety. Traffic Management Studies 2010; 5(18): 85-100. [In Persian]. 